\title{
Analytical and Numerical Investigation of Fracture Dominated Thermo-Fluid Flow in Geothermal Reservoir
}

\author{
H.H. Xu ${ }^{1,2}$, H.L. Xing ${ }^{1,3}$, D. Wyborn ${ }^{4}$, and P. Mora ${ }^{1,3}$ \\ ${ }^{1}$ ESSCC, The University of Queensland, St. Lucia, QLD 4072, Australia \\ ${ }^{2}$ South China Sea Institute of Oceanology, CAS, Guangzhou 510301, China \\ ${ }^{3}$ ACcESS, Major National Research Facility \\ ${ }^{4}$ Geodynamics Limitedd, Suite 6, Level 1, 19 Lang Parade, Milton, Brisbane, QLD 4064, \\ Australia
}

\begin{abstract}
Fluid flow in most of geothermal reservoirs is dominated by fractures and their distribution. In this study, the following process of cold water injection into a fractured geothermal reservoir is considered: the cold water from a injection well advances along the fractures and gradually extract heat from the adjacent rock matrix, and eventually arrives at a production well. Both analytical and finite element based numerical models are developed and applied to investigate the temperature and/or pressure evolution in the above process, and compared with each other.
\end{abstract}

Keywords: Fracture, analytical, Finite element, thermal-fluid flow.

\section{Introduction}

Fluid flow in most HDR/HFR geothermal reservoirs is dominated by fractures and their distribution. How the fractures affect the heat transfer between the fluid and the rock mass during injection process must be critically addressed. Several related researches have been reported [1,2]. The existing analytical model discussed by Bodvarsson [2,3] did not include the effect of conduction in fracture. In this paper, a model is proposed that includes the effect of conduction in the fracture. To investigate the advancement of the thermal fluid during the injection process into the fractured reservoir system, both the analytical and the finite element based numerical methods are developed and verified as follows through a simplified reservoir system consisting of a horizontal fracture intersecting an injection well and a production well.

\section{Analytical Solution}

The analytical model considers an injection well penetrating a reservoir with equally spaced horizontal fractures. Here, we assume the constant aperture $\mathrm{H}$ along the fractured zone, the constant injection rate $\mathrm{q}$ and an impermeable rock matrix (see Fig. 1). The 
differential equation governing the fluid temperature in the fracture can be derived by satisfying the energy conservation in the fracture zone as

$$
\rho_{a} c_{a} \frac{\partial T_{a}}{\partial t}=\kappa_{a} \frac{\partial^{2} T_{a}}{\partial x^{2}}-\frac{\rho_{w} c_{w} q}{H} \frac{\partial T_{a}}{\partial x}+\left.\frac{2 \kappa_{1}}{H} \frac{\partial T_{1}}{\partial z}\right|_{z=0}
$$

where $T_{a}$ and $T_{1}$ are the temperatures of fluid in the fracture and of the rock matrix, respectively. The temperature of the rock matrix is governed by the heat conduction equation as

$$
\rho_{1} c_{1} \frac{\partial T_{1}}{\partial t}=\kappa_{1} \frac{\partial^{2} T_{1}}{\partial z^{2}}
$$

The simultaneous solution of the equations using the Laplace transformation is derived. In the Laplace domain, the solutions for the fracture and the rock temperature are

Fracture zone

$$
u=\frac{1}{s} \exp \left[\left(\frac{1}{2 \delta}-\sqrt{\left.\frac{1}{4 \delta^{2}}+\frac{\lambda}{\delta}\right)} \xi\right]\right.
$$

Rock matrix

$$
\begin{gathered}
v=\frac{1}{s} \exp \left[\left(\frac{1}{2 \delta}-\sqrt{\left.\frac{1}{4 \delta^{2}}+\frac{\lambda}{\delta}\right)} \xi\right](\cosh \sqrt{s} \eta-\sinh \sqrt{s} \eta \tanh \sqrt{s})\right. \\
\lambda=\theta s+2 \sqrt{s} \tanh \sqrt{s}
\end{gathered}
$$

where $s$ is the Laplace parameter and $u, v$ is temperature variable in Laplace transform. Equation (3) and (4) are impossible to be inverted analytically from the Laplace domain, so a numerical inverter by Stehfest [4] is used here.

\section{Finite Element Based Numerical Equations}

From the above, the analytical solution is limited to the simplified ideal case. For simulating the practical complicated geothermal reservoir system, the finite element based numerical method is also developed. Numerical modeling of flow in porous/fractured media requires the coupling of various processes associated with the complex geological and hydrological setting of geothermal systems. For an example, the processes in the reservoir involve transport of fluid, heat and chemical species. In this research, the modeling will focus on coupling of fluid transport and heat transfer. The general conservation of mass for fluid is given by

$$
S_{s} \frac{\partial p}{\partial t}=\nabla \cdot\left[\frac{k}{\mu}(\nabla p+\rho g \nabla z)\right]
$$




$$
S_{s}=\rho g(\alpha+\phi \beta)
$$

From the energy conservation, the heat conductive-convective heat transfer in rock mass can be described as

$$
\begin{aligned}
c \rho \frac{d T}{d t} & =\nabla \cdot(\kappa \nabla T)-c_{w} \rho_{w} q \nabla T \\
q & =-\frac{k}{\mu}(\nabla p+\rho g \nabla z)
\end{aligned}
$$

Generally, the Galerkin's finite element method is applied to solve the above equation to simulate the conventional thermo-fluid flow in the porous media. It is feasible because the fluid flow in the conventional porous media is usually slow and thus the Pelect number ( $P e=q h / k$ with $h$ being a characteristic length) is less then 1 . However, if convection is dominant, such as in the fracture zone of a fracture dominated system, the Pelect number is normally much larger than 1 , and the above Galerkin formulation may suffer from spurious oscillations. So the Taylor-Galerkin formulation [5] is utilized here.

The thermo-fluid flow coupling is governed by the Eqs.(6), (8) and (9), which affect each other. The staggered method is applied here to treat this coupled problem $[6,7]$. Considering the above boundary conditions, the finite element formulation for fluid extra-pressure analysis can be deduced from Eq. (6) as

$$
\left(\frac{M}{\Delta t}+\frac{K}{2}\right) P_{t+\Delta t}=\left(\frac{M}{\Delta t}-\frac{K}{2}\right) P_{t}+Q
$$

where

$$
\begin{gathered}
M_{i j}=\int_{V} \rho S_{s} N_{i} N_{j} d V \quad K_{i j}=\int_{V} \rho \frac{k}{\mu} \frac{\partial N_{i}}{\partial x_{k}} \frac{\partial N_{j}}{\partial x_{k}} d V \\
Q_{i}=\int_{V} \rho^{2} g \frac{k}{\mu} \frac{\partial N_{i}}{\partial x_{3}} d V
\end{gathered}
$$

While, from Eqs. (8) and (9), the finite element formulation for heat transfers analysis can be rewritten as

$$
\left(\frac{M}{\Delta t}+\frac{K_{d}}{2}\right) T_{t+\Delta t}=\left(\frac{M}{\Delta t}-\frac{K_{d}}{2}-\left(K_{a}+K_{b d}\right)\right) T_{t}+Q_{t}
$$

Where

$$
M_{i j}=\int_{V} \rho c N_{i} N_{j} d V \quad K_{d i j}=\int_{V} k \frac{\partial N_{i}}{\partial x_{k}} \frac{\partial N_{j}}{\partial x_{k}} d V
$$




$$
K_{a i j}=\int_{V} \rho c q_{k} N_{i} \frac{\partial N_{j}}{\partial x_{k}} d V \quad K_{b d i j}=\frac{\Delta t}{2} \int_{V} \rho c q^{2} \frac{\partial N_{i}}{\partial x_{k}} \frac{\partial N_{j}}{\partial x_{k}} d V
$$

The above algorithm has been implemented to the existing finite element code for heat transfer analysis; the implicit algorithm is applied to solve the above equations (10) and (12) [6,7].

\section{Practical Example}

Geothermal energy manifests itself in spectacular fashion in many places on the earth's surface and has been widely recognized as a renewable green energy in the world. Several countries have started the related projects for developing the Hot Dry Rock (HDR) geothermal system which has been renamed as Hot Fractured Rock (HFR) in Australia. The Cooper Basin is entirely covered by the Mesozoic Eromanga Basin, where the measured surface heat flow is over $100 \mathrm{~mW} / \mathrm{m}^{2}$. Geodynamics Limited is developing the first Australian HFR geothermal reservoir system there for electricity generation. From the analysis of the microseismicity recorded during the hydraulic stimulation through the drilled well Habanero 1, the geothermal reservoir being developed in the Cooper Basin is determined as fracture dominated. The fracture zone is estimated to spans $30 \mathrm{~m}$ thickness along the vertical direction and is composed of a main fracture and a high permeability rock mass, which is further simplified as the following model (Figure 1) to be analysed by both the analytical and finite element methods, in which the permeability of the $30 \mathrm{~m}$ thick $(\mathrm{D}=15 \mathrm{~m})$ fracture zone is taken as 10 microDarcy, while the transmissibility of the main fracture with the aperture $\mathrm{H}=0.01 \mathrm{~m}$ down the middle of the fracture zone is 1 Darcy metre; and the temperature of injected fluid is $90^{\circ} \mathrm{C}$, the initial temperature of rock matrix is $260{ }^{\circ} \mathrm{C}$.

\subsection{The Analytical Result}

Figure 1 illustrates a schematic picture of the basic model for the analytical study. The following conditions are assumed here: Let the temperature in the vertical direction of the main fracture be uniform; the rock matrix be impermeable; horizontal conduction be neglected, and no heat flow along both the top and the bottom surfaces.

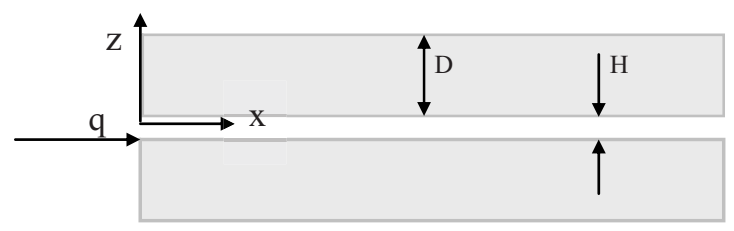

Fig. 1. Schematic of analystical model

Fig 2-5 show the analytical results with the parameters listed in table 1. From the results of temperature variation during 30 to 70 years at $X=400 \mathrm{~m}$ and $500 \mathrm{~m}$ (i.e. the distance of from the injection well) respectively shown in Figs 2 and 3 , we see the 
temperature of fluid in the fracture is almost the same as that of rock matrix after 30 years due to thermal conduction. Figs 4 and 5 show the fluid temperature variation at different distances and times. After 70 years the temperature has decreased from $260^{\circ} \mathrm{C}$ to $150^{\circ} \mathrm{C}$ at the production point $500 \mathrm{~m}$ away (Fig 5).

Table 1. Parameters used in analytical study

\begin{tabular}{|c|c|c|}
\hline & Fracture & $\begin{array}{c}\text { Rock } \\
\text { Matrix }\end{array}$ \\
\hline Thermal conductivity $\left(\mathrm{J} / \mathrm{ms}^{\circ} \mathrm{C}\right)$ & 2.8 & 3.0 \\
\hline Density $\left(\mathrm{kg} / \mathrm{m}^{3}\right)$ & 1000 & 2650 \\
\hline Specific heat $\left(\mathrm{J} / \mathrm{kg}^{\circ} \mathrm{C}\right)$ & 1000 & 800 \\
\hline Injection rate $\left(\mathrm{m}^{2} / \mathrm{s}\right)$ & $1.7 \mathrm{E}-5$ & 0 \\
\hline
\end{tabular}

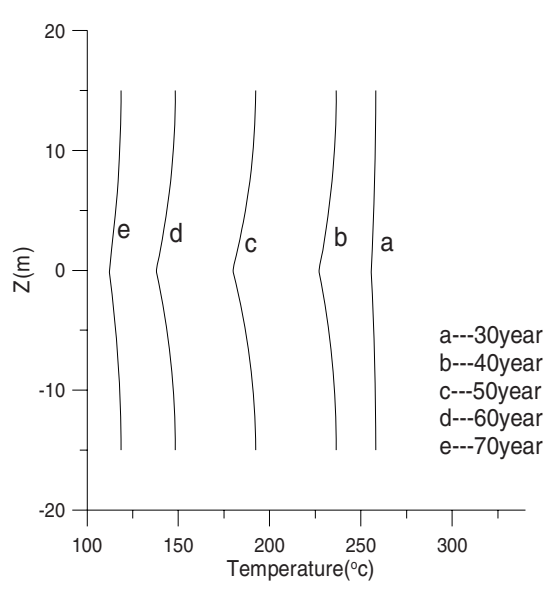

Fig. 2. Temperature variation at $X=400 \mathrm{~m}$

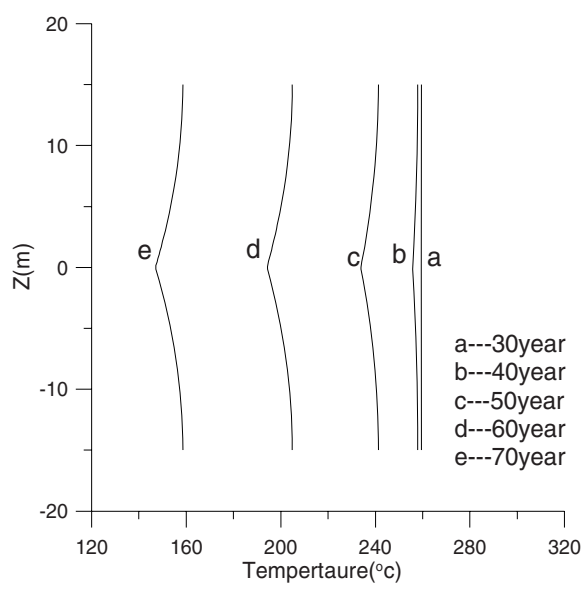

Fig. 3. Temperature variation at $X=500 \mathrm{~m}$

\subsection{Finite Element Based Numerical Analysis}

Most of the assumptions in the analytical case are not necessary for the numerical analysis. The aperture $\mathrm{H}$ of the fracture is constant but the fluid flow rate $\mathrm{q}$ is not constant, and the rock matrix is permeable, which is governed by Darcy equation. Similar to the analytical model, a $500 \mathrm{mx} 30 \mathrm{mx} 1 \mathrm{~m} 3 \mathrm{D}$ model with the main fracture of $\mathrm{H}=0.01 \mathrm{~m}$ in the middle is constructured and discretised into 20,000 8-node hexahedral elements. The initial and boundary temperature conditions are the same as for the analytical study. $70 \mathrm{Mpa}$ is set for the injection well and the pressure difference between the injection and production well is 7Mpa. No thermal flow is assumed along the other boundaries. All the parameters used here are listed in Table 2. 

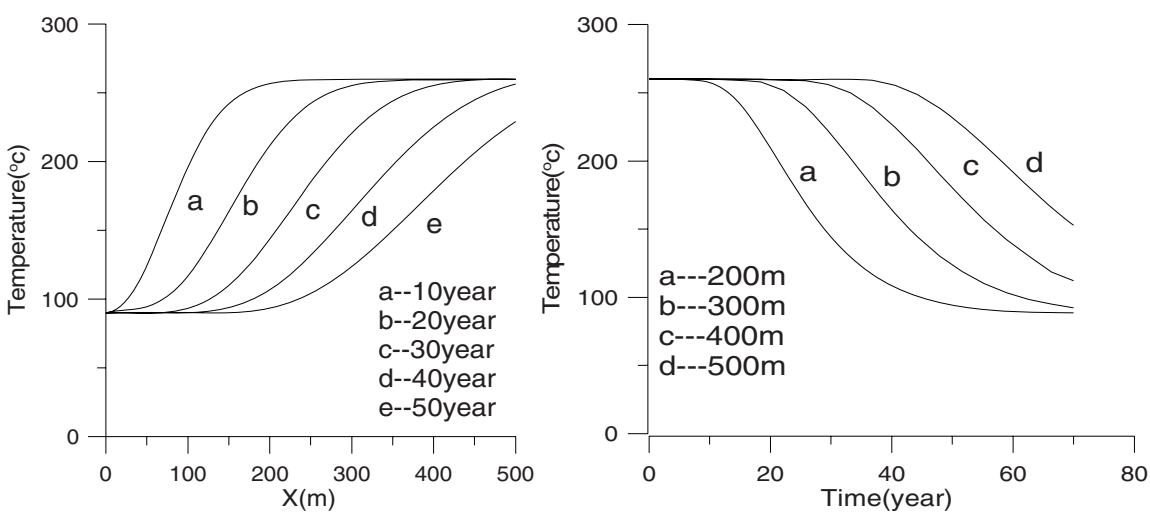

Fig. 4. Temperature evolution in fracture

Fig. 5. Temperature distribute in different points

Table 2. Parameters used in numerical study

\begin{tabular}{|l|l|c|}
\hline & Fracture & $\begin{array}{c}\text { Rock } \\
\text { matrix }\end{array}$ \\
\hline Thermal conductivity $\left(\mathrm{J} / \mathrm{m} \mathrm{s}^{\circ} \mathrm{C}\right)$ & 2.5 & 3.0 \\
\hline Density $\left(\mathrm{kg} / \mathrm{m}^{3}\right)$ & 1000 & 2650 \\
\hline Specific heat $\left(\mathrm{J} / \mathrm{kg}^{\circ} \mathrm{C}\right)$ & 4200 & 1000 \\
\hline Porosity & 1 & 0.01 \\
\hline Permeability $\left(\mathrm{m}^{2}\right)$ & $1.0 \mathrm{e}-10$ & $1.0 \mathrm{e}-14$ \\
\hline Compressibility $\left(\mathrm{Pa}^{-1}\right)$ & $5.0 \mathrm{e}-10$ & $5.0 \mathrm{e}-10$ \\
\hline Viscosity $(\mathrm{kg} / \mathrm{m} \mathrm{s})$ & $8.5 \mathrm{e}-3$ & $8.5 \mathrm{e}-3$ \\
\hline
\end{tabular}

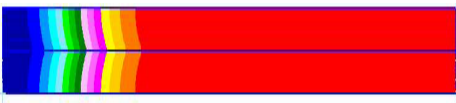

(a)
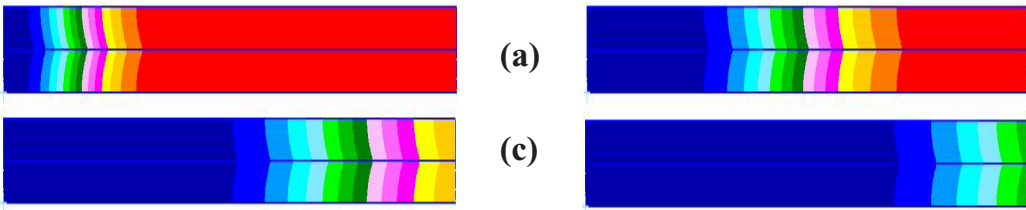

(c)

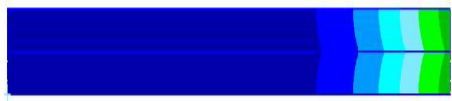

(d)

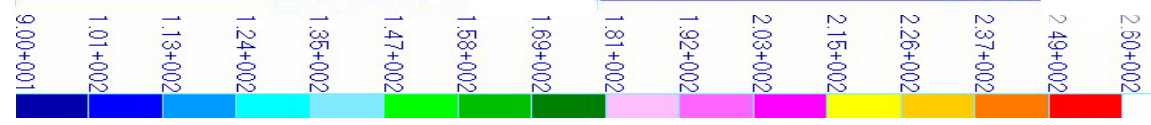

Fig. 6. Temperature evolution (years)(a -10 ,b- 30 ,c -50 d-, 70)

Figure 7 shows the pressure evolution at different times. The pressure varies drastically at the beginning stage around the injecting well, but reaches a stable state much more quickly than the temperature in Fig. 6, and then remains constant after about 50 hours.

This can also be seen from the curves of fluid flow velocity vs time in Figure 10, where the fluid velocity reaches a constant along the whole fracture at 50 hours. Figures 8 and 9 show the fluid temperature of in fracture zone evolution at different 
positions and time. Around the production well, the temperature remains above $150{ }^{\circ} \mathrm{C}$ after 50 years(Fig. 8). Assuming an allowable maximum temperature decrease of $40^{\circ} \mathrm{C}$ at the projection well, it will last up to 40 years as shown in Fig.9

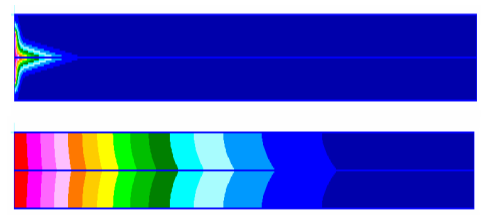

(a)

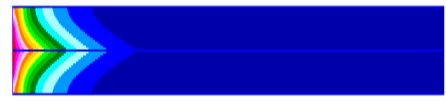

(b)

(c)

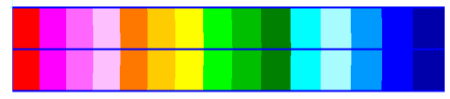

(d)

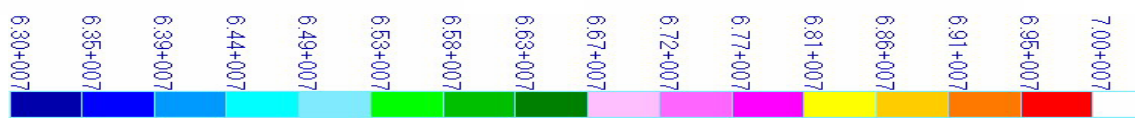

Fig. 7. Pressure evolution(a-0.1 hours ,b-1 hour, c -10hours, d -50 hours)

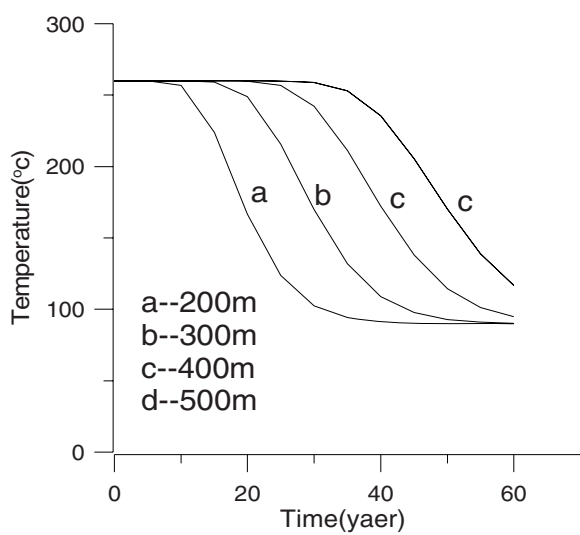

Fig. 8. Temperature at different point

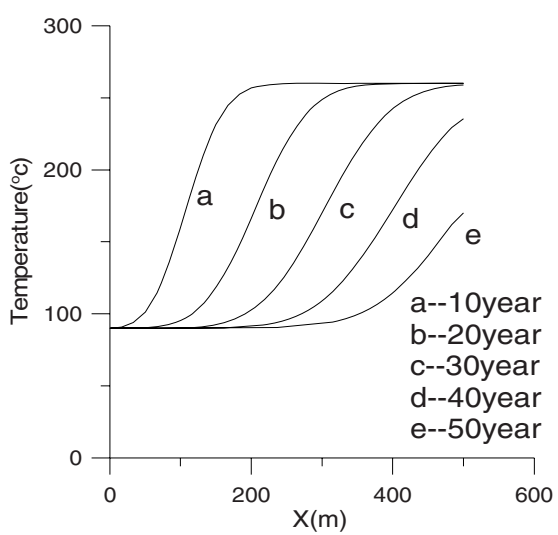

Fig. 9. Temperature at different time

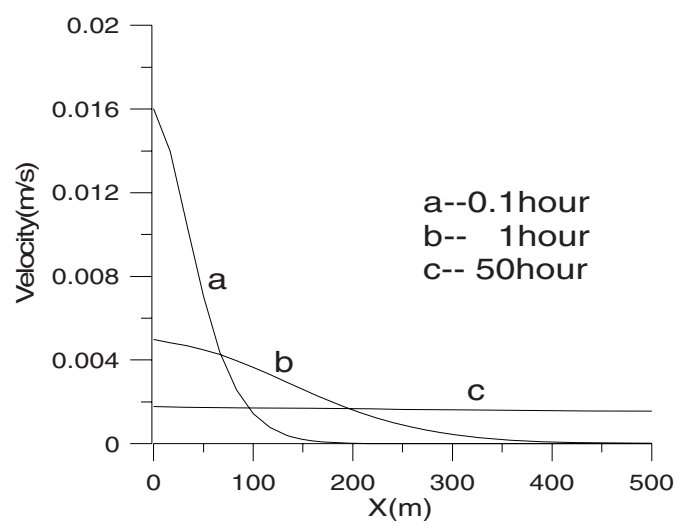

Fig. 10. The fluid velocity distribute in fracture 


\section{Discussions and Conclusion}

From the comparison of the above results from the analytical and the numerical solutions, the temperature evolution is almost the same at the different time and positions as shown in Figs 4 and 9, 5 and 8; the trend of both results is the same, but the temperature decrease is faster in the numerical solution than in analytical. In the analytical work, the assumption of an impermeable rock matrix was made and in the numerical solution the rock is permeable, the fluid in porous can take over heat of rock matrix. This demonstrates that (1) the assumptions made for the analytical solution, such as constant flow, are correct for such a long term case, because the fluid pressure/velocity reaches to a steady state in a very short time (about two days, Figs 7 and 10); (2) the numerical algorithm proposed here for the thermo-fluid coupling analysis works well; (3) The analytical solution is more suitable for a long term analysis, but not applicable for transient and/or complicated fault geometry, while the finite element based numerical analysis does well for the all the cases and may also be applicable to transient complicated analysis.

\section{References}

1. Gringarten, A.C., Witherspoon, P.A., and Ohnishi, A., Theory of heat extraction from aquifers with uniform regional flow, J. Geophys. Res., 80(8), (1975), 1120-1124.

2. Bodvarsson, G.S and Tsang, C.F., Injection and thermal breakthrough in fractured geothermal reservoirs, J. Geophys. Res., 87(2),(1982), 1031-1048

3. Bodvarsson, G.S., On the temperature of water flowing through fracture, J. Geophys. Res., 74(8), (1969), 1987-1992

4. Stefest, H., Numerical inversion of Laplace transforms, Commun. ACM, 13, (1979), 44-49.

5. Donea, J., A Taylor-Galerkin method of convective transport problem, Int. J, Num. Meth. Engg, 20, (1984), 101-119.

6. Xing, H.L., and Makinouchi, A., Three dimensional finite element modelling of thermomechanical frictional contact between finite deformation bodies using R-minimum strategy, Computer Methods in Applied Mechanics and Engineering, 191, (2002), 4193-4214

7. Xing, H.L., and Makinouchi, A., FE modelling of thermo-elasto-plastic finite deformation and its application in sheet warm forming, Engineering Computations - Int. J. ComputerAided Engineering and Software, 19,(2002), 392-410 